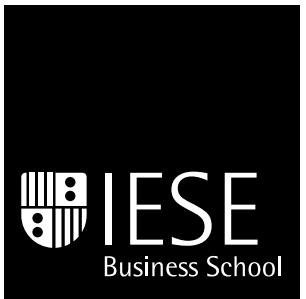

University of Navarra

THE EFFECT OF THE RATING SOURCE

IN ORGANIZATIONAL CITIZENSHIP BEHAVIOR:

A MULTITRAIT-MULTIMETHOD ANALYSIS

Pablo Cardona*

Alvaro Espejo**

\title{
RESEARCH PAPER No 474
}

October, 2002

* Professor of Managing People in Organizations, IESE

** Doctoral candidate, IESE

\section{Research Division}

IESE

University of Navarra

Av. Pearson, 21

08034 Barcelona - Spain 


\title{
THE EFFECT OF THE RATING SOURCE IN ORGANIZATIONAL CITIZENSHIP BEHAVIOUR: A MULTITRAIT-MULTIMETHOD ANALYSIS
}

\begin{abstract}
This study compares the ratings for three dimensions of organizational citizenship behaviour (OCB) provided by managers (self-ratings), their subordinates, and their colleagues (superiors and peers) in the Spanish branch of a multinational food company. Using hierarchical confirmatory factor analysis, we find strong method effects, indicating that ratings from different sources provide different information. A comparison among means shows that, in most cases, subordinate and self-ratings are significantly higher than colleague ratings. We also add to the recent research about the dimensionality of OCB by performing a correlation analysis among OCB dimensions that controls for method effects. Our results show that, when methods are taken into account, correlations among OCB dimensions are not significant.
\end{abstract}

Key words: Organizational citizenship behaviour, rating source, self-ratings, method effect, hierarchical confirmatory factor analysis 


\section{THE EFFECT OF THE RATING SOURCE IN ORGANIZATIONAL CITIZENSHIP BEHAVIOUR: A MULTITRAIT-MULTIMETHOD ANALYSIS}

\section{Introduction}

Over the last years, starting in 1983 (Smith, Organ, \& Near, 1983; Bateman \& Organ, 1983), there has been extensive research on the topic of organizational citizenship behaviour (OCB). Organ (1990) defined OCB as "those organizationally beneficial behaviours and gestures that can neither be enforced on the basis of formal role obligations nor elicited by contractual guarantee of recompense" (p. 46). Because citizenship behaviours are not necessarily directed towards the supervisor or any other specific person, there is no agreement on what is the best source of ratings for OCB (Moorman, 1991; Allen, Barnard, Rush, and Russell, 2000).

Researchers have mostly used measures of OCB coming from self-ratings or from supervisors. Organ (1990) argued that each source has its bias and that it is hard to say that one rating source is more valid than another. In their meta-analysis, Organ and Ryan (1995) found that the relationship between OCB and its attitudinal predictors was moderated by the use of self versus other ratings. Lately, most researchers have relied on supervisor ratings. As most of the studies looked for a model to explain the antecedents of OCB, the use of supervisor ratings avoided the problem of common method variance that exists when all the information comes from a single source (Podsakoff \& Organ, 1986; Cote \& Buckley, 1987; Lam, Hui, \& Law, 1999). However, Crampton and Wagner (1994) argued that it is not correct to condemn every use of self-reports, although moderation is required in their use, due to possible inflationary effects.

Recently, there have been studies suggesting that the rating source should depend on the research question. Van Dyne and LePine (1998) discussed the importance of selecting rating sources based on theory, because the meaning of a construct measured by the same items but rated by different individuals may not be the same. Lam et al. (1999) proposed the use of self-ratings when studying the behaviour of employees, and the use of supervisor ratings when investigating how supervisors appraise employees. Glick, Jenkins, and Gupta (1986) said that instead of assuming observer data as the best, it is more appropriate to use different sources to answer specific questions, whereas other researchers suggest the use of an average of different ratings (Allen et al., 2000). The field is far from reaching a definite conclusion on the rating source for OCB, therefore there is a need for further studies that compare the effects of different sources in OCB ratings.

Few studies have addressed specifically the issue of differences between OCB rating sources. However, these studies are still incomplete. In one of these studies, Becker and Vance (1993), using a direct product model analysis for multitrait-multimethod (MTMM) data, provided evidence that job incumbents, supervisors, and peers perceive OCB in 
different ways. But they do not include subordinates. More recently, Allen et al. (2000) introduced the perspective of subordinates and, using analysis of variance, found significant differences between rating sources. However, they analyze their MTMM data using only a visual inspection of the matrix, which may lead to confusing results (Millsap, 1990). Thus, there is still a need to study the effect of subordinate ratings using more robust techniques, such as confirmatory analysis (Becker \& Cote, 1994; Conway, 1996).

The use of different OCB rating sources may also provide new information about the dimensionality of OCB (Law, Wong \& Mobley, 1998; LePine, Erez, \& Johnson, 2002). While there is some evidence for considering OCB as a latent construct (LePine et al., 2002), the effect of the rating source has not been taken into account. In their meta-analysis, LePine et al. suggested the conceptualization of OCB as a latent construct based on two arguments. One is the high correlations among OCB dimensions. However, they accept that high correlations may be due to correlated method variance and suggest that further studies should use different sources to eliminate this variance. The other argument is that the relationship between different OCB dimensions and the most common predictors of OCB is similar. Yet, there is some evidence that the rating source is a strong moderator in these relationships (Organ \& Ryan, 1995).

In order to address these issues, we want to expand the literature on OCB rating sources by performing a hierarchical confirmatory factor analysis (HCFA) on the MTMM data (Marsh \& Hocevar, 1988; Marsh, 1993) including the perspectives of self, supervisors and peers, and subordinates. We will also perform an analysis of variance to compare our results with the ones obtained by Allen et al. Finally, we want to study how the information provided by different sources affects the dimensionality of the OCB construct. Therefore, we will correlate the different OCB dimensions, controlling for method effects, and we will study the relationship between each dimension of OCB and organizational commitment, one of its most widely studied predictors.

\section{Theory and Hypotheses}

In the last decade, most studies of OCB have used supervisor ratings. However, Allen et al. (2000) argued that many citizenship behaviours are more likely to be performed in front of co-workers and subordinates than in front of supervisors. Discussing the importance of 360-degree feedback, London and Beatty (1993) stated that subordinates are the best positioned to view and evaluate leadership behaviours. They emphasize that "managers should not be rating behaviours they do not observe" (p. 360). As Moorman (1991) suggested, only a part of the citizenship behaviours may be observed by supervisors. Along with the opportunities to observe citizenship behaviours, raters in different levels differ in the concept they have of the participant's role (Morrison, 1994; Lam, Hui, \& Law; 1999). Summarizing these ideas, Mount, Judge, Scullen, Sytsma, and Hezlett (1998) state that "raters from different levels observe different aspects of performance and may also use different standards when judging performance" (p. 560).

Some empirical studies (Becker and Vance, 1993; Van Dyne and LePine, 1998; Allen et al., 2000) provide evidence of these differences among sources. Becker and Vance found that method effects were present in the data: ratings were different depending on whether respondents were job incumbents, supervisors, or peers. Using direct product analysis, they compared a one-method factor model with a three-method factor model (one per rater), and found that the latter had a significantly better fit with the data. Allen et al. (2000) analyzed the MTMM matrix with the Campbell and Fiske's (1959) criteria, and also 
found method effects: self-reported ratings were not significantly correlated with other ratings. Van Dyne and LePine (1998) found the same pattern of correlations between supervisor, peer, and self-ratings. Therefore, we propose the following hypothesis:

Hypothesis 1: Method factors will exert a significant effect in OCB ratings.

Morrison (1994) and Lam, Hui, and Law (1999) found that supervisors differ from job incumbents in their classification of in-role and extra-role behaviours. These studies show that supervisors have a broader definition of job roles than employees do. Thus, supervisors may classify some behaviours as part of the employees' job, while these employees classify those same behaviours as OCB. This difference in job definition may produce lower supervisor's OCB ratings than those of employees. On the other hand, Bolino (1999) suggests that some OCB behaviours may be due to impression management and therefore may be performed in order to be observed by supervisors. This effect may inflate the supervisor ratings compared to other ratings. However, it is unclear how these two opposite effects play together and when one is greater than the other.

Allen et al. (2000) used analysis of variance to determine the existence of significant differences between rating sources. They compared the ratings of job incumbents, supervisors, and subordinates for five OCB dimensions: conscientiousness, sportsmanship, civic virtue, courtesy, and altruism. They found that mean superior and self-ratings were not significantly different in all OCB dimensions, and that they were higher than subordinate ratings for courtesy and altruism. Therefore, we propose the following hypothesis:

Hypothesis 2: Subordinate ratings will be significantly lower than other ratings for different OCB dimensions.

The analysis of different OCB dimensions measured by different raters may help to understand the relationship between the dimensions and the general OCB construct. Law et al. (1998) referred to OCB as an example of a multidimensional construct that has unspecified relations with its dimensions. LePine et al. (2002) performed a meta-analysis to address this issue and they found some evidence supporting a latent construct representation of OCB. Nonetheless, they warn that the evidence is not enough to categorically reject other options. LePine et al. based their conclusions on the high correlations among the different OCB dimensions and on the similar relationships that each dimension has with predictors. As an alternative explanation, however, they admit that high correlations may be due to correlated method variance. They suggest that further research should eliminate correlated method variance by measuring OCB dimensions with different sources and/or methods. As our study considers different raters for each dimension, we can control for method effects and observe the correlations among dimensions. Thus, we propose the following hypothesis about the relationship among OCB dimensions:

Hypothesis 3: Correlations among OCB dimensions will be positive and significant, after controlling for method effects.

We also address the relationship between each dimension and predictors of OCB for different OCB rating sources. Becker and Vance (1993) suggested that, in order to have a better understanding of the OCB construct, future research should relate different OCB dimensions with organizational commitment and satisfaction. LePine et al. (2002) observed no apparent differences in the relationships between different dimensions and the most common predictors of OCB, but they do not differentiate between rating sources. In 1995, Organ and 
Ryan found positive and significant correlations between affective commitment and different dimensions of OCB, and that these relationships were significantly higher for self-reported ratings than for observer ratings. Therefore, we propose the following hypothesis:

Hypothesis 4: Organizational commitment will have a positive and significant impact on all OCB dimensions for different OCB rating sources.

\section{Method}

\section{Sample and Procedure}

Participants were managers in the Spanish branch of a multinational food company. The firm's Human Resource Department selected all participants and collected the data as part of a larger 360-degree performance evaluation. All of the handled surveys were returned. Six of the participants' surveys could not be used because of incomplete evaluations.

The sample consisted of 73 managers, 73 superiors, 179 peers, and 209 subordinates. As our sample included one superior per participant, we were asked by the company to group superiors with peers in order to assure the superior's confidentiality when providing feedback to participants. Supervisors and peers had been highly correlated in previous studies in performance evaluation (Harris and Schaubroeck, 1988), although Becker and Vance (1993) found moderate correlations for OCB data. For clarity purposes, we will refer to this category as colleagues. On average, the colleagues' rating includes one superior and three peers, so this category should be closer to the peers' perspective than to the superiors' one. In the sample, there are three to five subordinates per participant.

\section{Measures}

We wrote the questionnaire in English and then translated it into Spanish using the back-translation method (Brislin, 1986). During the translation process, the wording of some items was adapted to achieve a meaning in Spanish closer to the original meaning in English. All negatively worded items were reworded into a positive form. Participants answered using a seven-point Lickert scale ranging from absolutely disagree to absolutely agree. The scale is presented in the Appendix. The answers were confidential and all feedback was given as aggregated data.

We measured OCB using 12 items representing three traits or dimensions of citizenship behaviour. Those dimensions are altruism, conscientiousness, and loyalty, each consisting of four items. To measure conscientiousness and loyalty, we selected items from the obedience and loyalty categories developed by Van Dyne et al. (1994). We used four items from Farh, Podsakoff, and Organ (1990) to represent the altruism dimension. Organizational commitment was measured with four items selected from Allen and Meyer's (1990) scales of affective and normative commitment.

\section{Multitrait-Multimethod Analyses}

Campbell and Fiske (1959) proposed a method to determine the validity of a construct by measuring multiple traits with multiple methods (MTMM). Although their guidelines have been used in a wide variety of studies, they have also received many 
criticisms (Widaman, 1985; Marsh, 1989, 1993; Millsap, 1990). Millsap warned that direct comparisons of correlations in a MTMM matrix might not reveal the presence of substantial method variance. Becker and Vance (1993) used a direct product model to analyze MTMM data. This method provides more accurate results than Campbell and Fiske's method, but still uses an average of the items in each factor. Marsh (Marsh \& Hocevar, 1988; Marsh, 1993) proposes a new method to analyze data with multiple items: hierarchical confirmatory factor analysis (HCFA). This method has several advantages over traditional MTMM analysis: it provides a test for the factor structure and allows for different contributions of the items to each factor. This is important when different raters answer the same items because otherwise convergent validities tend to be positively biased by autocorrelations among specific indicator variances (Marsh, 1993).

HCFA models use first order factors to represent each trait-method combination. The evaluation of this first-order model tests the assumed factor structure, implicit in traditional MTMM approaches. Second-order factors represent trait and method effects: there is a second-order factor for each trait and each method (rater).

Figure 1 provides a graphical representation of the complete model with correlated traits and uncorrelated methods.

Figure 1. HCFA Model with Correlated Trait factors and Uncorrelated Method Factors

$\begin{array}{cccccc}\text { Trait } & \text { Trait Second- } & \text { Rater (Method) } & \text { First } & \text { Observed } & \text { Error } \\ \text { Correlations } & \text { Order Factors } & \begin{array}{c}\text { Second-Order } \\ \text { Factors }\end{array} & \text { Order } & \text { Fcores } & \text { Correlations } \\ & & \text { Factors } & & \end{array}$

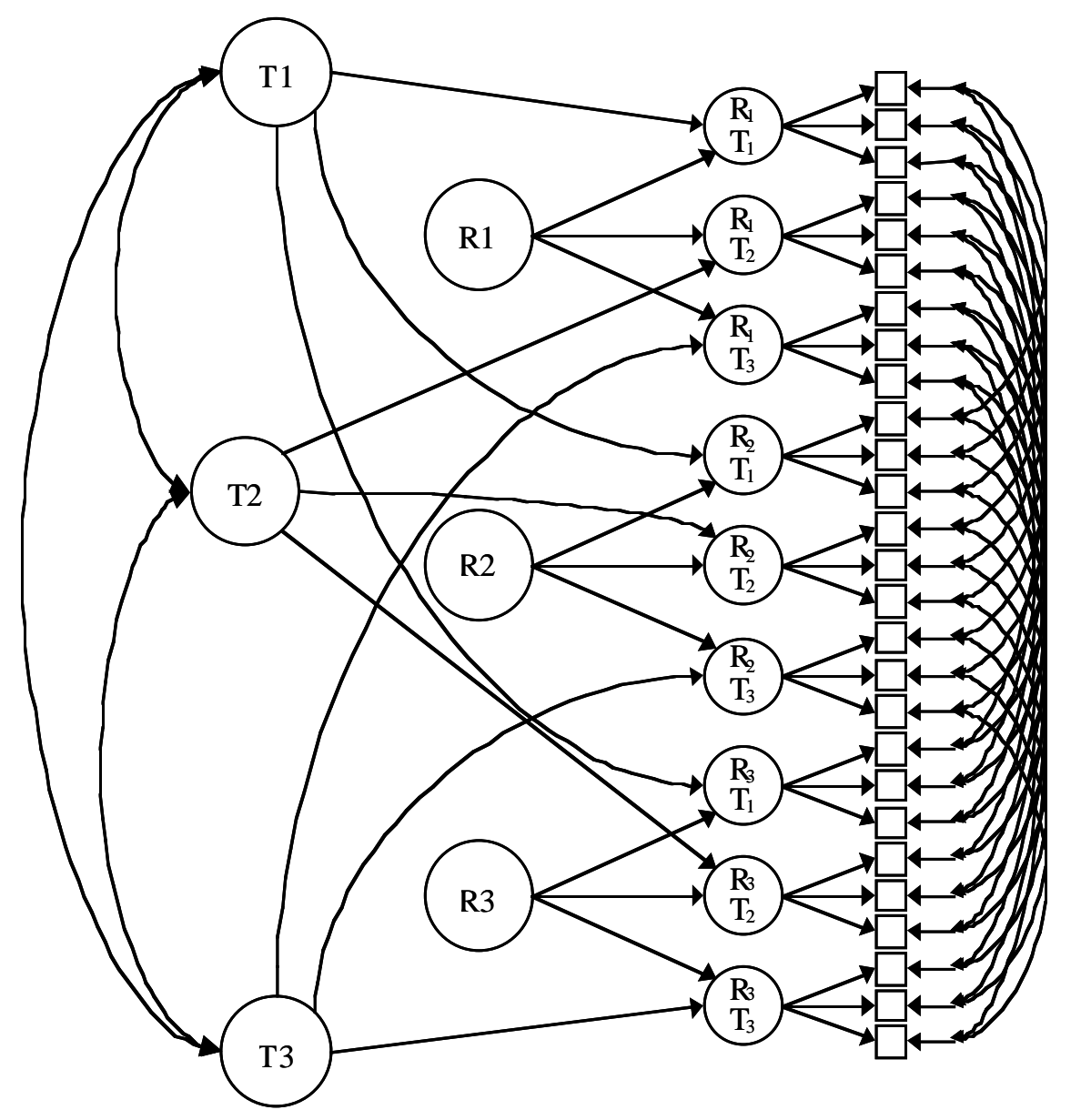


Conway (1996), working with performance appraisal data from different raters, compared the performance of three MTMM models: confirmatory factor analysis, correlated uniqueness (CU), and direct product (DP). His results showed a significantly better performance of the CU model in terms of proper solutions and fit to the data. Marsh (1993) found that incorporating CU to HCFA improves the model's fit and accuracy. For these reasons, we will also include a correlated uniqueness model to our HCFA models.

\section{Results}

We performed the HCFA using EQS version 5.7b (Bentler, 1995). We calculated maximum likelihood (ML) estimates and assessed the goodness-of-fit of each model with the comparative fit index (CFI) and the root-mean-square error of approximation (RMSEA). We interpreted these fit statistics according to conventional cutoff values; therefore, we considered as good fit values a CFI over 90 (Dunn, Everitt, \& Pickles, 1993) and an RMSEA below .08 (Browne \& Cudeck, 1993).

Prior to the confirmatory factor analysis, we performed an exploratory factor analysis to check the a priori factor structure. We ran a separate principal components analysis, with a varimax rotation, on the OCB items for each rating source. The factor loadings for self-ratings suggested the dropping of three items, one in each OCB dimension. Table 1 shows the results of the exploratory factor analysis for the remaining items and for the different raters.

Table 1. Factor Loadings of Exploratory Factor Analyses for Different Ratings Sources of OCB

\begin{tabular}{|c|c|c|c|c|c|c|c|c|c|c|}
\hline \multirow{3}{*}{ Item } & \multirow{3}{*}{ OCB Dimension } & \multicolumn{9}{|c|}{ Factor } \\
\hline & & \multicolumn{3}{|c|}{ Self } & \multicolumn{3}{|c|}{ Colleague } & \multicolumn{3}{|c|}{ Subordinate } \\
\hline & & 1 & 3 & 4 & 1 & 3 & 4 & 1 & 3 & 4 \\
\hline 1 & Altruism & .83 & .22 & .30 & .83 & .18 & .26 & .85 & .26 & .27 \\
\hline 2 & Altruism & .64 & .41 & .14 & .78 & .24 & .23 & .74 & .43 & .21 \\
\hline 4 & Altruism & .75 & .04 & .22 & .79 & .14 & .17 & .78 & .21 & .30 \\
\hline 10 & Conscientiousness & .30 & .80 & .21 & .16 & .83 & .25 & .32 & .65 & .40 \\
\hline 11 & Conscientiousness & .43 & .68 & .01 & .12 & .89 & .24 & .35 & .80 & .29 \\
\hline 12 & Conscientiousness & -.01 & .83 & .16 & .31 & .77 & .13 & .21 & .88 & .15 \\
\hline 13 & Loyalty & .18 & .46 & .69 & .25 & .22 & .83 & .23 & .24 & .84 \\
\hline 14 & Loyalty & .26 & .26 & .86 & .21 & .23 & .89 & .23 & .20 & .90 \\
\hline 15 & Loyalty & .20 & -.06 & .88 & .24 & .20 & .86 & .29 & .23 & .80 \\
\hline
\end{tabular}

\section{Visual Examination of the MTMM Matrix}

Table 2 presents the descriptive statistics and the multitrait-multimethod matrix. Following Marsh and Hocevar (1988), the correlations in the table are the correlations between the first-order factors representing the different combination of traits and raters. These latent constructs are inferred from the multiple indicators of each scale. 
Table 2. Descriptive Statistics and Multitrait-Multimethod Matrix

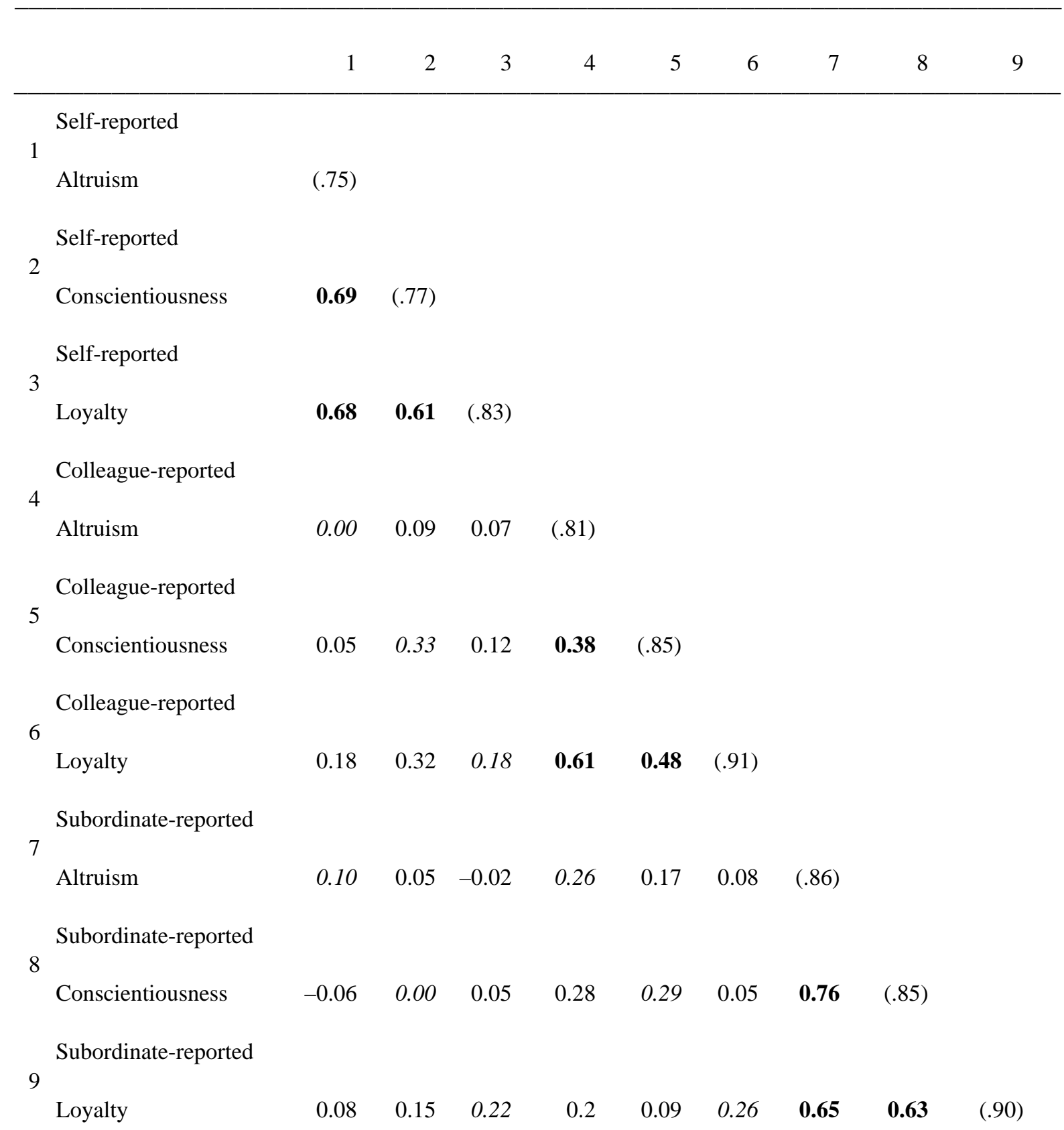

Cronbach's alphas for each scale are shown on the diagonal (reliability diagonal). Italic numbers represent monotrait-heteromethod correlations (validity diagonals). Bold numbers represent heterotrait-monomethod correlations.

$\mathrm{N}=67 . \mathrm{r} \geq .26, \mathrm{p}<.05 . \mathrm{r} \geq .41, \mathrm{p}<.01$ 
Examination of the validity diagonals indicates the existence of significant relationships between colleague ratings and subordinate ratings. However, only one correlation among self-ratings and others is significant. Thus, there is some evidence for convergence validity only in the case of observer ratings. The values in the validity diagonal are lower than the correlations in heterotrait-monomethod triangles. This suggests the presence of strong method effects. Besides, validity coefficients are not generally higher than values in its column and row in the same heterotrait-heteromethod triangle, so there is little evidence for discriminant validity. In summary, observation of the MTMM matrix suggests strong method effects and weak trait effects. The results of the HCFA and of the comparison among the different models, which we will present next, will support these findings.

\section{Significance of Models and Comparisons among Models}

We performed a HCFA for the MTMM data considering only trait effects (Model 1), only method (rater) effects (Model 2), and both trait and method effects (Model 3). We also considered a fourth model containing trait factors and correlated uniqueness. These models were compared with one another and with a first-order model as a benchmark (Model 0).

Results of the comparison are presented in Table 3.

Table 3. Comparison of Fit Statistics for OCB Antecedent Model with Different Rating Sources

\begin{tabular}{|c|c|c|c|c|}
\hline Model & $\chi^{2}$ & $\chi^{2} / d f$ & CFI & RMSEA \\
\hline Model 0 (Baseline) & $354.95(279 d f)$ & 1.27 & .928 & .066 \\
\hline Model 1 (Trait only) & $456.47(285 d f)$ & 1.60 & .838 & .097 \\
\hline Model 2 (Method Only) & $377.40(288 d f)$ & 1.31 & .916 & .070 \\
\hline Model 3 (3T, 3M) & $355.78(276 d f)$ & 1.29 & .925 & .068 \\
\hline Model 4 (3T, CU) & $354.62(276 d f)$ & 1.28 & .926 & .067 \\
\hline \multicolumn{5}{|c|}{$\begin{array}{l}\text { Differences in } \chi^{2} \text { between models } 1 \text { and } 3 \text { (nested models) are significant at } p<.01 \\
\text { Differences in } \chi^{2} \text { between models } 2 \text { and } 3 \text { (nested models) are significant at } p<.10\end{array}$} \\
\hline
\end{tabular}

Models 0 and 2 were well specified, whereas models 1, 3, and 4 presented Heywood cases (variance terms outside their permissible range). Although this could imply model misspecification, we believe that in these cases the improper estimates are due to sampling fluctuation (Marsh, 1993). The small sample size and the high method effects affect the performance of the models (Becker \& Vance, 1993; Conway, 1996). According to Marsh's criteria, if the model converges and the $95 \%$ confidence interval around all parameters contains proper values, the solutions are "technically improper but not seriously ill-defined" (p. 63). This 
means that the results of the model are acceptable. All our models meet Marsh's criteria. Becker and Vance's (1993) solution also contained a Heywood case for the complete model, and they fixed the parameter to the boundary value. This is the same choice we used.

Fit statistics for the complete second-order factor model (model 3) are better than the fit statistics for models 1 and 2, and are close to the statistics for model 0 , the baseline model. The fit was improved only slightly by the introduction of the CU model (model 4). Fit statistics for second-order models cannot possibly be better than those for model 0 , because the models are nested (Marsh \& Hocevar, 1988).

The addition of method factors to the trait only model significantly improves the fit of the model $(\mathrm{p}<.01)$. This supports hypothesis 1 that method factors will exert a significant effect in OCB ratings. In contrast, the addition of trait factors to the method only model only improved its fit marginally $(\mathrm{p}<.10)$. This, along with the higher fit statistics of model 2 compared to model 1, suggests that the differences in method have a larger impact than the differences in traits. Moreover, every relationship between the trait-method construct and its corresponding method factor was highly significant. On the other hand, relationships among the trait-method constructs and the trait factors were not always significant. In particular, the general altruism factor was not significantly related to any of the altruism-method factors. This reveals large differences in the way each rating source perceived the manager's altruism.

\section{Mean Differences}

We performed an analysis of variance to observe whether mean differences among different ratings were significant. In order to obtain the means for the different dimensions, we had to average the three items on each scale. We found significant differences among sources for altruism and for conscientiousness. Using Tukey's honestly significant difference test we conducted comparisons between pairs of different sources. For altruism, only the difference between self and colleagues was significant $(\mathrm{p}<.05)$. For conscientiousness, the differences between self and colleagues, and between subordinates and colleagues, were significant $(\mathrm{p}<.05)$. Table 4 presents the results of the analysis of variance for each dimension and compares them with the results obtained by Allen et al. (2000) for the same dimensions.

The results do not support hypothesis 2 that subordinate ratings will be significantly lower than other ratings for different OCB dimensions. Whereas we expected self and colleague ratings to be the highest, colleagues in our sample provided the lowest scores for altruism, while self-ratings were the lowest for conscientiousness. Subordinate ratings were the highest in both dimensions. 
Table 4. Analysis of Variance for OCB: Comparison with previous study (Allen et al., 2000)

\begin{tabular}{|c|c|c|c|c|c|c|c|c|}
\hline \multirow[b]{2}{*}{ Dimension } & \multirow[b]{2}{*}{ Study } & \multicolumn{2}{|c|}{ Self } & \multicolumn{2}{|c|}{ Colleagues ${ }^{1}$} & \multicolumn{2}{|c|}{ Subordinates } & \multirow{2}{*}{$\frac{\text { ANOVA }}{F \text {-values }}$} \\
\hline & & $M^{2}$ & $S D$ & $M^{2}$ & $S D$ & $M^{2}$ & $S D$ & \\
\hline \multirow[t]{2}{*}{ Altruism } & Current & $5.75_{\mathrm{a}}$ & .69 & $5.43_{\mathrm{b}}$ & .58 & 5.70 & .80 & $3.99^{*}$ \\
\hline & Allen $e t a l$. & $4.05_{\mathrm{a}}$ & .51 & $4.04 \mathrm{a}$ & .59 & $3.62_{\mathrm{b}}$ & .72 & $19.32^{* *}$ \\
\hline \multirow[t]{2}{*}{ Conscientiousness } & Current & $5.28_{\mathrm{a}}$ & .85 & $5.64_{b}$ & .54 & $5.88_{\mathrm{b}}$ & .64 & $12.74^{* *}$ \\
\hline & Allen $e t a l$. & 4.55 & .39 & 4.55 & .50 & 4.44 & .58 & 2.04 \\
\hline Loyalty ${ }^{3}$ & Current & 6.17 & .74 & 5.93 & .51 & 6.09 & .70 & 2.37 \\
\hline \multicolumn{9}{|c|}{$\begin{array}{l}\text { Note. Means in the same row with different subscripts differ at } p<.05 \text { in the Tukey honestly significan } \\
\text { difference comparison. }\end{array}$} \\
\hline $\begin{array}{ll}1 & \text { Sample in Aller } \\
2 & \text { The current stud } \\
3 & \text { Study by Allen } \\
* & \mathrm{p}<.05 \\
* * & \mathrm{p}<.01\end{array}$ & $\begin{array}{l}\text { et al. conside } \\
\text { y uses a seven } \\
\text { t al. did not c }\end{array}$ & $\begin{array}{l}\text { y superi } \\
\text { scale, } \\
\text { ar the lo }\end{array}$ & $\begin{array}{l}\text { s, wh } \\
\text { nereas } \\
\text { lty di }\end{array}$ & $\begin{array}{l}\text { colleagh } \\
\text { study } \\
\text { nsion. }\end{array}$ & $\begin{array}{l}\text { includ } \\
\text { Allen }\end{array}$ & $\begin{array}{l}\text { also pe } \\
\text { al. uses }\end{array}$ & ive-poir & ale. \\
\hline
\end{tabular}

\section{Dimensionality of $O C B$}

Hypothesis 3 that correlations among OCB dimensions will be positive and significant, after controlling for method effects, was not supported. As expected, correlations among OCB dimensions were positive and significant. However, when we controlled for method effects, the correlations lost their significance. Table 5 presents the correlations among OCB dimensions with and without controlling for method effects.

Table 5. Correlations among OCB dimensions

\begin{tabular}{lccc}
\hline & Altruism & Conscientiousness & \multicolumn{1}{c}{ Loyalty } \\
\hline Altruism & - & $.93^{* *}$ & $.79^{* *}$ \\
Conscientiousness & .31 & - & $.62^{* *}$ \\
Loyalty & .23 & .14 & - \\
\hline Correlations among OCB dimensions without controlling for method effects are presented above the diagonal. \\
Correlations among OCB dimensions controlling for method effects are presented below the diagonal. \\
$* *$ p $<.01$
\end{tabular}


We found partial support for hypothesis 4 that organizational commitment will have a positive and significant impact on all OCB dimensions for different OCB rating sources. Table 6 presents the results of the different models that relate commitment with each OCB dimension. When altruism, conscientiousness, and loyalty were measured using self-ratings, the relationship was positive and highly significant, but the significance disappeared when others rated OCB.

Table 6. Differential effects of Organizational Commitment on the dimensions of OCB

\begin{tabular}{|c|c|c|c|c|c|}
\hline \multirow{2}{*}{ Rater } & \multirow{2}{*}{ OCB Dimension } & \multirow{2}{*}{$\begin{array}{c}\text { Impact of } \\
\text { Organizational Commitment } \\
\text { (Standardized Coefficient) }\end{array}$} & \multicolumn{3}{|c|}{ Fit of the Model } \\
\hline & & & $\chi^{2}(13 d f)$ & CFI & RMSEA \\
\hline Self & Altruism & $.63^{* *}$ & 25.31 & .930 & .121 \\
\hline Self & Conscientiousness & $.59^{* *}$ & 13.94 & .995 & .036 \\
\hline Self & Loyalty & $.63^{* *}$ & 19.90 & .967 & .091 \\
\hline Colleague & Altruism & .15 & 20.12 & .960 & .092 \\
\hline Colleague & Conscientiousness & .10 & 14.05 & .995 & .038 \\
\hline Colleague & Loyalty & .22 & 16.69 & .985 & .067 \\
\hline Subordinate & Altruism & .00 & 17.18 & .977 & .071 \\
\hline Subordinate & Conscientiousness & -.04 & 9.86 & 1.00 & .000 \\
\hline Subordinate & Loyalty & .05 & 15.51 & .989 & .056 \\
\hline$* * \mathrm{p}<.01$ & & & & & \\
\hline
\end{tabular}

\section{Discussion}

The objective of this research was to perform an in-depth study on the different rating sources for OCB. Previous literature on OCB rating sources had considered subordinates ratings only through mean and correlation comparisons in the MTMM matrix. We go one step further by incorporating the perspective of subordinates into a MTMM analysis through a hierarchical confirmatory factor analysis. By avoiding the use of an average of the scales, we capture the specific variance of each item.

The MTMM analysis shows large method effects. This result indicates that the selection of the rating source is critical when doing research on OCB. The good fit obtained by the method-only model and by the complete model (three traits and three methods) supports Allen et al.'s (2000) results that subordinates provide a distinct rating of OCB. 
Another contribution of this study is that it provides new insights about the dimensionality of OCB. LePine et al. (2002) suggest that high correlations normally observed among different dimensions of OCB may indicate that OCB is a latent construct. However, they also warn that these high correlations may be due to correlated method variance. Our study shows that correlations among traits are low once methods are controlled. This supports LePine et al.'s alternative explanation and questions the idea of the OCB latent construct. On the other hand, there are no apparent differences in the relationship of the OCB dimensions with organizational commitment. This is congruent with the latent construct explanation. Still, the rating source is an important mediator in this relationship, so results must be accepted carefully. Thus, further research should continue exploring the dimensionality of $\mathrm{OCB}$ before the latent construct representation is finally accepted.

This study also contributes to identify other differences among OCB dimensions that cannot be identified with only one rating source. Specifically, factors representing conscientiousness and loyalty for each source were related to general conscientiousness and loyalty factors. However, factors representing altruism for each source were not related to a general altruism factor. Altruism, thus, emerges as a special dimension for which the different ratings do not reflect the same underlying factor. In other words, different rating sources perceive managers' altruism in very different ways. Differences in perceptions between altruism and other dimensions are consistent with William and Anderson's (1991) distinction between OCBI and OCBO. The first category corresponds to behaviours that benefit specific individuals and, through them, contribute to the organization. Altruism belongs to this category. The second category corresponds to behaviours that benefit the organization in general. Conscientiousness and loyalty belong to this category. Independent of the observer's hierarchical position, managers' behaviours directed towards the organization may be observed by more people in the organization than managers' behaviours directed to specific individuals. Thus, ratings for OCBO may be more homogeneous than ratings of OCBI.

Mean comparisons in our study differ from previous research. Allen et al. (2000) found that the means of superior and self-ratings were consistently higher than the mean of subordinate ratings. In our sample, however, the mean of subordinate ratings was significantly higher than the mean of colleague ratings. Our results are consistent with the studies about role definition that suggest lower ratings from people at higher levels of the organization. This does not mean that impression management is not present in our study, but that it affects OCB ratings in a different way. Although the two studies are not completely comparable, we suggest that the differences between them may be due to cultural factors. There are at least two alternative explanations of how impression management in different cultures may contribute to the differences between these two studies.

The first possible explanation is the higher presence of impression management in subordinates' answers in the Spanish study, especially if the subordinates think that their managers can have access to the results. Subordinates could inflate the ratings as a "favour" to their managers, expecting to gain their approval (Gardner \& Martinko, 1988). In this study, however, subordinates were explicitly told that ratings were confidential and that results would be aggregated and used only for feedback purposes rather than for administrative purposes. Thus, we do not expect this effect to be very significant. A second possible explanation is the higher presence of impression management in American managers' behaviours. These behaviours would be mostly directed towards peers and superiors, rather than towards subordinates. This would result in unparallel perceptions from different rating sources, specifically in lower subordinate ratings. Further research should look at how cultural differences may impact OCB ratings from different sources. 
There are several limitations in this study that may affect the present findings. One limitation is that we cannot distinguish between superior and peer ratings. In fact, colleagues had the lowest heterotrait-monomethod correlations, possibly due to differences between superior and peer ratings. Besides, our colleagues variable is not directly comparable with other variables in previous studies. As we have seen before, on average, the colleagues' rating includes one superior and three peers. Thus, for comparison purposes, this variable should be closer to the peers' perspective than to the superiors' one. Another limitation in this study is the small sample size. Even if the total number of respondents was high, considering managers, superiors, peers, and subordinates, as we had to pair all ratings with self-ratings, only 67 cases were available for the analyses. The small sample size is probably the cause of some ill-defined solutions.

The aim of this study was not to resolve how to deal with differences among OCB sources. Thus, the question of what is the best measure of OCB remains open. Future research should discern whether it is better to use composite measures or to use specific rating sources for different research questions. The ongoing discussion about the dimensionality of OCB may help to relate some OCB dimensions with particular raters. Knowing the causes behind the differences among sources may be useful in order to understand whether one source could be more valid than another in a particular case. Therefore, future studies should explore possible causes, such as opportunities to observe behaviours and role definitions. Integration between the OCB literature and the performance evaluation literature may also help to advance in this direction. Finally, future studies should address the influence of culture on OCB, studying how country-specific factors affect OCB ratings.

\section{References}

Allen, N. J., \& Meyer, J. P. (1990). The measurement and antecedents of affective, continuance and normative commitment to the organization. Journal of Occupational Psychology, 63, 1-18.

Allen, T. D., Barnard, S., Rush, M. C., \& Russell, J. E. A. (2000). Ratings of organizational citizenship behaviour: Does the source make a difference? Human Resource Management Review, 10, 97-114.

Bateman, T. S., \& Organ, D. W. (1983). Job satisfaction and the good soldier: The relationship between affect and employee "citizenship". Academy of Management Journal, 26, 587-595.

Becker, T. E., \& Cote, J. A. (1994). Additive and multiplicative method effects in applied psychological research: An empirical assessment of three models. Journal of Management, 20, 625-641.

Becker, T. E., \& Vance, R. J. (1993). Construct validity of three types of organizational citizenship behaviour: An illustration of the direct product model with refinements. Journal of Management, 19, 663-682.

Bentler, P. M. (1995). EQS Structural Equations Program Manual. Encino, CA: Multivariate Software, Inc.

Bolino, M. C. (1999). Citizenship and impression management: Good soldiers or good actors? Academy of Management Review, 24, 82-98. 
Borman, W. C., \& Motowidlo, S. J. (1993). Expanding the criterion domain to include elements of extrarole performance. In N. Schmitt \& W. C. Borman (Eds.), Personnel selection in organizations (pp. 71-98). San Francisco: Jossey-Bass.

Brislin, R. W. (1986). The wording and translation of research instruments. In W. J. Looner \& J. W. Berry (Eds.), Field Methods in Cross-Cultural Research. Beverly Hills, CA: Sage.

Browne, M. W., \& Cudeck, R. (1993). Alternative ways of assessing model fit. In K. A. Bollen \& J. S. Long (Eds.), Testing Structural Equation Models. Newbury Park, CA: Sage.

Campbell, D. T., \& Fiske, D. W. (1959). Convergent and discriminant validation by multitrait-multimethod matrix. Psychological Bulletin, 56, 81-105.

Conway, J. M. (1996). Analysis and design of multitrait-multirater performance appraisal studies. Journal of Management, 22, 139-162.

Cote, J. A., \& Buckley, M. R. (1987). Estimating trait, method, and error variance: Generalizing across 70 construct validation studies. Journal of Marketing Research, 24, 315-318.

Crampton, S. M., \& Wagner III, J. A. (1994). Percept-percept inflation in microorganizational research: an investigation of prevalence and effect. Journal of Applied Psychology, 79, 67-76.

Dunn, G., Everitt, B., \& Pickles, A. (1993). Modelling Covariances and Latent Variables Using EQS. London: Chapman and Hall.

Farh, J. L., Podsakoff, P. M., \& Organ, D. W. (1990). Accounting for organizational citizenship behaviour: Leader fairness and task scope versus satisfaction. Journal of Management, 16, 705-721.

Gardner, W. L., \& Martinko, M. J. (1988). Impression management in organizations. Journal of Management, 14, 321-338.

Glick, W. H., Jenkins, G. D., \& Gupta, N. (1986). Method versus substance: How strong are underlying relationships between job characteristics and attitudinal outcomes? Academy of Management Journal, 29, 441-464.

Harris, M. M., \& Schaubroeck, J. (1988). A meta-analysis of self-supervisor, self-peer, and peer-supervisor ratings. Personnel Psychology, 41, 43-62.

Lam, S. K., Hui, C., \& Law, K. S. (1999). Organizational citizenship behaviour: Comparing perspectives of supervisors and subordinates across four international samples. Journal of Applied Psychology, 84, 594-601.

LePine, J. A., Erez, A., \& Johnson, D. E. (2002). The nature and dimensionality of organizational citizenship behaviour: A critical review and meta-analysis. Journal of Applied Psychology, 87, 52-65.

London, M., \& Beatty, R. W. (1993). 360-degree feedback as a competitive advantage. Human Resource Management Review, 32, 353-372. 
Marsh, H. W. (1989). Confirmatory factor analyses of multitrait-multimethod data: Many problems and a few solutions. Applied Psychological Measurement, 13, 335-361.

Marsh, H. W. (1993). Multitrait-multimethod analyses: Inferring each trait-method combination with multiple indicators. Applied Measurement in Education, 6, 49-81.

Marsh, H. W., \& Hocevar, D. (1988). A new, more powerful approach to multitraitmultimethod analyses: Application of second-order confirmatory factor analysis. Journal of Applied Psychology, 73, 107-117.

Millsap, R. E. (1990). A cautionary note on the detection of method variance in multitraitmultimethod data. Journal of Applied Psychology, 75, 350-353.

Moorman, R. H. (1991). Relationship between organizational justice and organizational citizenship behaviours: Do fairness perceptions influence employee citizenship? Journal of Applied Psychology, 76, 845-855.

Morrison, E. W. (1994). Role definitions and organizational citizenship behaviour: The importance of the employee's perspective. Academy of Management Journal, 37, 1543-1567.

Mount, M. K., Judge, T. A., Scullen, S. E., Sytsma, M. R., \& Hezlett, S. A. (1998). Trait, rater and level effects in 360-degree performance ratings. Personnel Psychology, 51, 557-576.

Organ, D. W. (1990). The motivational basis of organizational citizenship behaviour. Research in Organizational Behaviour, 12, 43-72.

Organ, D. W., \& Ryan, K. (1995). A meta-analytic review of attitudinal and dispositional predictors of organizational citizenship behaviour. Personnel Psychology, 48, 775-802.

Podsakoff, P. M., MacKenzie, S. B., Paine, J. B., \& Bachrach, D. G. (2000). Organizational citizenship behaviours: A critical review of the theoretical and empirical literature and suggestions for future research. Journal of Management, 26, 513-563.

Podsakoff, P. M., \& Organ, D. W. (1986). Self-reports in organizational research: Problems and prospects. Journal of Management, 12, 69-82.

Smith, C. A., Organ, D. W., \& Near, J. P. (1983). Organizational citizenship behaviour: Its nature and antecedents. Journal of Applied Psychology, 68, 655-663.

Van Dyne, L., Graham, J. W., \& Dienesch, R. M. (1994). Organizational citizenship behaviour: Construct redefinition, measurement, and validation. Academy of Management Journal, 37, 765-802.

Van Dyne, L., \& LePine, J. A. (1998). Helping and voice extra-role behaviours: Evidence of construct and predictive validity. Academy of Management Journal, 41, 108-119.

Widaman, K. F. (1985). Hierarchically nested covariance structure models for multitraitmultimethod data. Applied Psychological Measurement, 9, 1-26.

Williams, L. J., \& Anderson, S. E. (1991). Job satisfaction and organizational commitment as predictors of organizational citizenship and in-role behaviours. Journal of Management, 17, 601-617. 
Appendix

THE EFFECT OF THE RATING SOURCE IN ORGANIZATIONAL CITIZENSHIP BEHAVIOUR: A MULTITRAIT-MULTIMETHOD ANALYSIS

\section{Questionnaire Items}

\section{Organizational Commitment}

1. Right now I would not abandon this organization, among other reasons, because my work here is sufficiently attractive for me.

2. Working in this organization is worthwhile, among other reasons, because my work offers me opportunities to learn and grow professionally.

3. Right now I would not abandon this organization because of a sense of obligation toward the people I work with.

4. At this moment, it will not be difficult for me to find another organization where I could feel substantially more identified.

\section{Organizational Citizenship Behaviour}

\section{Altruism}

1. Helps coworkers with work related problems.

2. Helps orient new coworkers voluntarily.

3. Takes time out of his or her schedule to adapt to other employees' needs. b

4. Shows care and courtesy towards coworkers even in times of professional or personal tension.

\section{Conscientiousness}

5. Rarely misses work, even when there is a good reason. $\mathrm{ab}$

6. Makes few mistakes when performing job. ${ }^{\text {a }}$

7. Completes obligations with extreme care.

8. Always meets deadlines. ${ }^{\text {a }}$

Loyalty

9. Defends organization when employees criticize it. ${ }^{\text {a }}$

10. Defends organization against outside threats. ${ }^{\text {a }}$

11. Tells outsiders that he (she) is proud to work in this organization. ${ }^{\text {a }}$

12. Actively promotes organization's products and services to potential users. ${ }^{b}$

\footnotetext{
a These items were negatively worded in the original scales.

$\mathrm{b}$ These items were dropped after exploratory factor analysis.
} 